Tür Turizm Araştırmalari Dergisi
2021, 5(2): 1238-1257.
ISSN: $2587-0890$ Dergi web sayfasi: $\underline{\text { https://www.tutad.org }}$

\title{
Türk Mutfağında Füzyon Uygulamalarına Yaklaşım Ölçeğinin Geçerlenmesi
}

\author{
Doç. Dr. Leyla ÖZGEN, Gazi Üniversitesi, Sağlik Bilimleri Fakültesi, Ankara, e-posta: leylaozgen@gmail.com \\ ORCID: https://orcid.org/0000-0002-5737-8691
}

Dr. Öğr. Üyesi Mehmet GÜLLÜ, Tokat Gaziosmanpaşa Üniversitesi, Zile Dinçerler Turizm İşletmeciliği ve Otelcilik Yüksekokulu, Tokat, e-posta: mehmet.gullu@gop.edu.tr

ORCID: https://orcid.org/0000-0001-6060-1842

Öğr. Gör. Aygün KALIN, Tekirdağ Namık Kemal Üniversitesi, Şarkoy Meslek Yüksekokulu, Tekirdağ, e-posta: akalin@nku.edu.tr

ORCID: https://orcid.org/0000-0002-4662-7082

Öğr. Gör. Ebubekir YILMAZ, Bilecik Şeyh Edebali Üniversitesi, Osmaneli Meslek Yüksekokulu, Bilecik, e-posta: ebubekir.yilmaz@bilecik.edu.tr ORCID: https://orcid.org/0000-0003-3770-2332

Öz

Bu çalışmada Türk mutfağında füzyon uygulamalarına yaklaşım ölçeğinin geçerlenmesi ve bireylerin füzyon mutfak uygulamalarına (yeni yiyeceklere) yaklaşımlarının tespit edilmesi amaçlanmıştır. Bu bağlamda Fransız ve İtalyan mutfağından yararlanılarak Türk mutfağına ait ürünlerle füzyon mutfağı uygulamaları belirlenmiştir. Çalışma örneklemini Ankara ili Kültür ve Turizm Bakanlığında çalışan kamu personelinden kolaylıkla bulunabilen örnekleme yöntemiyle gönüllü olarak katılan 110'u kadın 147'si erkek toplam 257 birey oluşturmuştur. Çalışmada kullanılan Türk mutfağında füzyon uygulamalarına yaklaşım ölçme aracının geçerlik ve güvenirlik katsayısının uygun olduğu tespit edilmiştir. Türk mutfağında füzyon uygulamalarına yaklaşım ölçeğinin "Haşhaşlı otlu krep tadarım", "Tahinli galetta tadarım", "Kuru meyvelerle hazırlanmış biscotti tadarım" gibi ifadelerden oluşan "yenilikçi" alt boyutu ile cinsiyet değişkenine göre, erkeklerin kadınlara göre hem Türk Fransız mutfağı hem de Türk İtalyan mutfağı füzyon uygulamalarında yenilikçi olduğu tespit edilmiş̧ir. Türk mutfağında füzyon uygulamalarına yaklaşım ölçeğinin "şüpheci" alt boyutu ile yurtdışı deneyimi değişkenine göre, yurt dışı deneyimi olan bireylerin yurtdışı deneyimi olmayan bireylere göre daha şüpheci olduğu saptanmıştır. Türk mutfağında füzyon uygulamalarına yaklaşım ölçeğinin "Devekuşu yumurtası ile hazırlanmış sebzeli Frittata (İtalyan omleti) tatmam", "Chianti şarabı ile marine edilmiş kuzu şiş tatmam" gibi ifadelerden oluşan "gelenekçi”" alt boyutta, erkeklere göre kadınların Türk İtalyan mutfağı füzyon uygulama ürünlerinde daha az gelenekçi olduğu bulunmuştur. Türk mutfağında füzyon mutfak uygulamaları, geleneksel mutfak kültürüne alışkın toplumlar için yeni bir mutfak akımı olup, bu akımda sunulan ürünlerin tamamı yeni birer gastronomik ürün olarak ele alınabilir.

Anahtar Kelimeler: Füzyon Mutfağı, Gastronomi, Neofobi, Türk Mutfağı, Fransız ve İtalyan Mutfağı.

Makale Gönderme Tarihi: 10.02.2021

Makale Kabul Tarihi: 03.06.2021

\section{Önerilen Atıf:}

Özgen, L., Güllü, M., Kalın, A. ve Yılmaz, E. (2021). Türk Mutfağında Füzyon Uygulamalarına Yaklaşım Ölçeğinin Geçerlenmesi, Türk Turizm Araştırmaları Dergisi, 5(2): 1238-1257.

(c) 2021 Türk Turizm Araştırmaları Dergisi. 


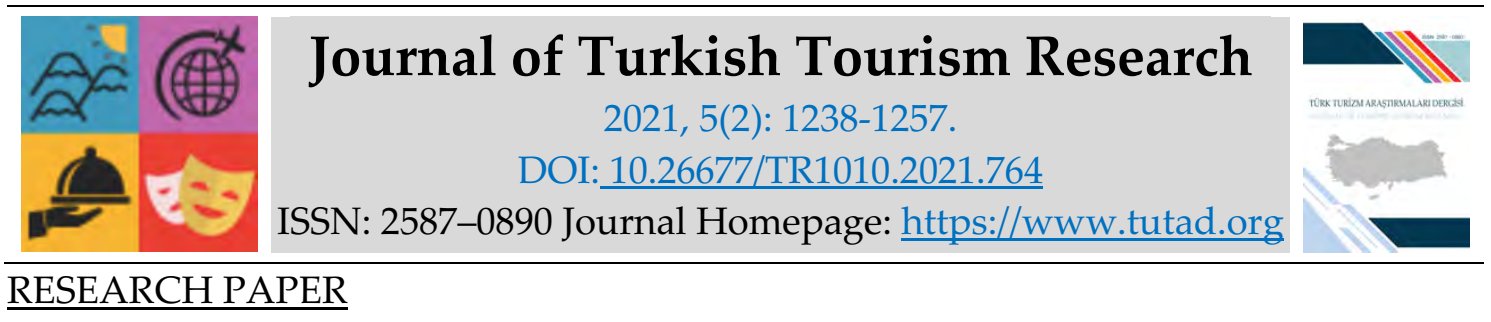

\title{
Validation of the Scale of Approach to Fusion Applications in Turkish Cuisine
}

Associate Prof. Dr. Leyla ÖZGEN, Gazi University, Faculty of Health Sciences, Ankara, e-mail: $\underline{\text { leylaozgen@gmail.com }}$ ORCID: https://orcid.org/0000-0002-5737-8691

Assistant Prof. Dr. Mehmet GÜLLÜ, Tokat Gaziosmanpaşa University, Zile Dinçerler School of Tourism and Hotel Management, Tokat, e-mail: mehmet.gullu@gop.edu.tr

ORCID: https://orcid.org/0000-0001-6060-1842

Lecturer Aygün KALIN, Tekirdağ Namık Kemal University, Şarkoy Vocational School, Tekirdağ, e-mail: akalin@nku.edu.tr

ORCID: https://orcid.org/0000-0002-4662-7082

Lecturer Ebubekir YILMAZ, Bilecik Şeyh Edebali University, Osmaneli Vocational School, Bilecik, e-mail: ebubekir.yilmaz@bilecik.edu.tr

ORCID: https://orcid.org/0000-0003-3770-2332

\begin{abstract}
This study aimed to validate the "Approach to fusion applications in Turkish cuisine" scale and determine individuals' approach to fusion cuisine applications (new foods). In this context, fusion cuisine applications using products from Turkish cuisine making use of Italian and French cuisine were determined. The study sample consisted of 257 individuals, 110 females and 147 males, from among civil servants working in the Ministry of Culture and Tourism in Ankara who participated voluntarily using the convenience sampling method. The validity and reliability coefficient of the measuring tool for approach to fusion applications in Turkish cuisine in this study was found to be suitable. Looking at the gender variable in the "innovative" subscale of the "Approach to fusion practices in Turkish cuisine" scale, consisting of expressions such as "I will try pancakes with poppy seeds," "I will try breadcrumbs and sesame," and "I will try biscotti prepared with dried fruits," men were found to be more innovative than women with products that were a fusion of Turkish and French cuisine. Looking at the "experience abroad" variable in the "skeptical" subscale of the "Approach to fusion practices in Turkish cuisine" scale, it was determined that individuals with experience abroad are more skeptical than those without such experience. In the "traditionalist" subscale of the "Approach to fusion applications in Turkish cuisine" scale, consisting of expressions such as "I will not try vegetable Frittata (Italian omelets) prepared with ostrich eggs," "I will not try lamb skewers marinated in Chianti," women were found to be less traditional than men with products that were a fusion of Turkish and Italian cuisine. Fusion cuisine practices in Turkish cuisine are a new culinary trend for societies that are accustomed to traditional cuisine culture, and all the products offered in this trend can be seen as new gastronomic products.
\end{abstract}

Keywords: Fusion Cuisine, Gastronomy, Neofobia, Turkish Cuisine, French and Italian Cuisine.

Received: 10.02 .2021

Accepted: 03.06.2021

\section{Suggested Citation:}

Özgen, L., Güllü, M., Kalın, A. and Yılmaz, E. (2021). Validation of the Scale of Approach to Fusion Applications in Turkish Cuisine, Journal of Turkish Tourism Research, 5(2): 1238-1257.

(C) 2021 Türk Turizm Araştırmaları Dergisi. 


\section{Gíriş}

Toplumları belirleyen en önemli özellik kültürleridir. Kültürleri tanımlamak için ikili karşıtlıkların zorunlu görüldüğü merkez-çevre, kendi-öteki gibi ayrıştırıcı ifadelerin kullanımı daha üretken bir bağlamda kullanılmaya başlanmıştır. Homi Bhabha'nın hibrite (melezlik) kavramı ile bu merkez-çevre ilişkilerinin kültürel alandaki üreticiliğine dikkat çekilmektedir (Benedict, 1991; Bhabha, 1994). Farklı kültürlerin yorumlanmasında melezlik kavramı kullanılmaktadır. Melezlik kuramına ve Homi Bhabha'ya atıfta bulunulma nedeni, farklı iki kültürün karşılaşma alanını bizim/ sizin karşıtlığı dışında yorumlamasıdır (Demirkol, 2013). Dünyada, yerelliklerin birbirinden kopuk bağlantılar şeklinde küreselleşmenin dönüştürdüğü deneyimler olarak yaşandığı savın açıklaması olan melezlik kavramıdır. Melezlik dünyanın farklı yerlerindeki kültürlerin birbirine karışmasıdır (Küçük ve Kahyaoğlu, 2013). Melezleşme biraz kaybetmeyi ama biraz da kazanmayı içerdiği ifade edilmiştir (Hannerz, 1998).

Fransız ihtilalinden günümüze kadar geçen sürede gastronomide oldukça farklı değişimler yaşanmış, her bir dönemin bilimsel bilgeliğinin öncülügü ile gastronomide hızlı değişimler yaşanmıştır. Bunlara en iyi örnek olan tarihin ilk yıllarına dayalı olan füzyon mutfağı tekrar ortaya çıkmıştır (Poulain, 2005; Del Moral, 2020). Ancak, bireylerin sağlıklı yaşamla daha çok ilgilenmesi Türk mutfağının ve farklı ülke mutfaklarının oluşturduğu bir sentez aracilığıyla füzyon mutfağı üzerinden yapıldığı tespit edilmiştir (Girgin vd., 2017). Özellikle Türk mutfağında füzyon mutfak uygulamaları ile destinasyonda sunulan yiyeceklerin, bireylerin hem alışkın olduğu lezzetlere yakın olması hem de yeni, farklı ve özgün tat arayışları nedeniyle füzyon mutfağının daha çok tercih edilebileceği ifade edilmiştir (Tarınç vd., 2019).

Füzyon mutfağı, farklı bölge ve ülkelere ait yemek pişirme yöntemleri kullanılarak yerel yiyecek malzemelerinin özenli ve düzenli bir şekilde ayn tabakta buluşması ile oluşan yeni ve özgün yemek yapma tekniği olarak tanımlanmaktadır (Kırım, 2005; Sandıkçı ve Çelik, 2007; Mil, 2009). Bir başka çalışmada da füzyon mutfağı, farklı dünya mutfaklarına ait yemeklerin birbiriyle karıştırılması olarak tanımlamaktadır (Doğdubay vd., 2017). Bu kavram, yemeğin ve mutfak kültürünün uluslararası olması anlamını da taşımaktadır (Kırım, 2005). Medyada yer alan yemek programları ve yarışmalar, şeflerin yazdığı yemek kitapları gibi yiyeceklere yönelik internette çok sayıda sitenin bulunması füzyon mutfak kavramının ve uygulanmasının daha fazla bilinmesine neden olmuştur (Chiaro ve Rossato, 2015: 239).

\section{LITERATÜR TARAMASI}

Türk mutfağının, Türklerin yaşadıkları coğrafyada şekillenen ve birçok uygarlığın izlerini taşıyan geniş bir kültüre sahip olduğu vurgulanmıştır (Arman, 2011). Başka bir çalışmada Türk mutfağ 1 Orta Asya'dan günümüze değin süren tarihsel bir süreç olarak görülmektedir. Asya ve Anadolu topraklarının sunmuş olduğu ürün çeşitliliği, tarih boyunca başka kültürlerle yaşanan etkileşim, Selçuklu ve Osmanlı saraylarında yeni gelişen tatların varlığı, Mezopotamya'dan kaynaklanan Anadolu mutfağının varlığı gibi etkenler Türk mutfağının renkliliğini ve çeşitliliğini sağlayan unsurlar olduğu belirtilmiştir (Güler, 2010).

Türk Mutfağı hakkında yabancı şeflerin görüşlerinde Türk mutfağının zengin, tarihsel bir geçmişe ve Dünya mutfakları arasında da özel bir yere sahip olduğu ifade edilmiştir (Çakıcı ve Eser, 2016). "Dünya Mutfakları" içerisinde en çok adı geçen mutfakların Çin, Fransız ve Türk Mutfakları olduğu, bununla birlikte Fransız Mutfağının gelişmesinde İtalyan Mutfağının da katkı sağladığı vurgulanmıştır (Girgin vd., 2017). Fransız yemeklerinin, yüksek nitelikli yemekler olduğu ve yapım teknikleriyle diğer ülkelere de aktarıldığı belirtilmiştir (Albors-Garrigos vd., 2020:2). Fransızlar, tarih boyunca farklı coğrafyalara etki ederek, kendi yemek kültürünün 
yayılmasına neden olabildiği gibi Fransız mutfağı ile Osmanlı mutfağının birbiri arasında melezleşme olduğu görülmüştür (Oktay ve Sadıkoğlu, 2018:144). Günümüzde Uzakdoğu coğrafyasında bile Fransız mutfağının etkisinde söz edilmektedir (Kawasaki ve Shimomura, 2015:2). Malezya mutfağının da Fransız devrimiyle birlikte Fransız mutfağından etkilenerek geliştiği vurgulanmaktadır (Zainal Abidin vd., 2020:2). Fransız mutfağının; birbirine denk olarak adlandırılan ve zirvede yer alan mutfaklar arasında dahi "eşitlerin birincisi" olduğu ifade edilmiştir (Lane, 2019:10). Fransız yemekleri, 2010 yılında UNESCO tarafından "Somut Olmayan Kültürel Miras" listesine alınmış; yüksek nitelikli, yaratıcı ve kültürel endüstri ürünleri olarak kabul edilmiştir (Presenza vd., 2017:81). Fransız mutfağının; dünyanın en tanınmış mutfaklarından biri olduğu, yemek pişirmenin sanat olarak değerlendirildiği, pişirdikleri etlerin genellikle şarap ile marine edildiği, şarabın yemekleri hazırlamada sos olarak kullanıldığı gibi yemeklerin yanında da tüketildiği, özellikle şarap ve peynir uyumunun mutfaklarda önemli bir yerde bulunduğu ifade edilmiştir (Yıldız, 2016: 3). Fransız mutfağında yemek sırası genellikle soğuk ordövrlerle başlamakta, bunları çoğunlukla konsome adı verilen bir tür çorba izlemektedir. Ana yemekten önce çeşitli sıcak ordövrler servis edilmektedir. Fransız mutfağında ana yemek genellikle çeşitli sebze garnitürleri ile birlikte sunulan et yemeği şeklindedir. Ana yemekle tatlı veya meyve arasında da peynir servisi yapıldığı belirtilmiştir (Köksal Sezgin, 2020).

İtalyan mutfağının Avrupa'nın ilk gelişmiş mutfağı olduğu (Brittin, 2011), inovasyona açı ve etkileşime uygun bir karakter gösterdiği belirtilmektedir (Petruzzelli ve Savino, 2015:688). Malezya mutfağını etkileyen ve şekillendiren Avrupa mutfakları olarak örneğin; Fransa ve İtalya gibi mutfakların yer aldığı ve etkilediği belirtilmiştir (Zainal Abidin vd., 2020:1). Ancak mutfaklarında kullanılan birçok bileşenin başka coğrafyalardan geldiği ifade edilmektedir. Araplardan pirinç, safran, şeker, baharatlar, limon ve portakal, Katalan coğrafyasından zeytinyağı ve sarımsak, Yunan ve Fenikelilerden zeytin ağacı ve nohut, Amerika kıtasından ise domates, mısır, vanilya ve çikolatanın İtalyan kültürüne yerleştiği vurgulanmaktadır (Weichselbaum vd., 2009; Brittin, 2011; Kittler vd., 2012; Renna vd., 2014; Özen, 2016). İtalya'da yemekler üç öğün şeklinde yenmektedir. Geleneksel olarak günün en önemli öğünü öğlen yemeği iken, bu alışkanlık değişerek günümüzde yerini akşam yemeğine bırakmıştır. Kahvaltı genellikle kahve ve cornetto adı verilen hamur işi atıştırmalık ile geçiştirilmektedir. İtalyan mutfağında deniz mahsulleri, av hayvanları, risotto, makarna, ravioli ve pizza ağırlıklı olarak tüketilen yiyeceklerdir. Ayrıca meyvelerden yapılan tatlılar da oldukça yaygın tüketilmektedir (Katona-Apte, 2003; MacVeigh, 2009; Parasecoli, 2011). İtalyan mutfağı, hem dünya mutfakları arasında yer alması hem de Michelin yıldızlı şeflerine sahip olması nedeniyle önemli olduğu belirtilmiştir (Presenza vd., 2017:82). Michelin yıldızlı şeflerinin, yenilikçi ve yaratıcı fikirleriyle dünya mutfakları arasında gastronominin yeniden oluşmasına sebep olduğu ifade edilmiştir (Vargas-Sanchez ve Lopez-Guzman, 2015:32). İtalyan mutfağında hazırlanan yemeklerin sağlıklı olması, yemeklerin besin olarak görülmesinden ziyade yerken bir kültürdeki insanların dinlendiği ve keyif alınan, eğlence-sohbet havasında geçen bir gastronomi kültürü olarak görüldüğü belirtilmiştir (Tarr, 2016). Bu yönüyle İtalyan mutfağ füzyon mutfağı uygulamalarına oldukça elverişli bir mutfak olarak değerlendirilmiştir. Türk Mutfağını Türkiye'de yaşayan farklı kültürlerin mutfağının oluşturduğu ve bunların bir sentez olduğu ve tanıtımının füzyon mutfak üzerinden yapılması gerektiği ifade edilmiştir (Girgin vd., 2017).

Füzyon mutfağı oluşturulması için Türk mutfağı, Fransız ve İtalyan mutfağı tercih edilmiştir. Fransız ve İtalyan mutfağı Somut Olmayan Kültürel Miras başlığı altında hem “UNESCO Kültür Miras Listesinde" yer alması (Yorgancı, 2018), hem de İtalyan mutfağının Akdeniz Mutfağı olması nedeniyle tercih edilmiştir. Türk mutfağına benzer özellikleri olması nedeniyle füzyon mutfağı uygulaması oluşturulmak istenmiştir. Füzyon mutfak uygulamalarının Türk Mutfağını gerçek kimliğinden uzaklaştırdığını ve yeni bir şekle bürünmesine sebep olduğunu belirten 
çalışmalar bulunmaktadır (Denizer, 2008). Ancak, füzyon mutfakta elde edilen tabakta farklı bir ürün hazırlandığının kabul edilmesi, o yemeğin doğrudan Türk mutfağını yansıtmadığını ve burada mutfakları dejenere etmek değil, iki farklı mutfağa ait özellikleri tek bir tabakta yeni bir yapıda birleştirmek olduğunu bilmek gerekmektedir (Can vd., 2012). Karamustafa vd., (2016)'nın yaptıkları çalışmada, Türkiye'de füzyon mutfak uygulaması olan restoranların Uzakdoğu, İtalyan ve Fransız mutfak lezzetlerini kullanarak yeni ürünler oluşturdukları, Türk mutfağındaki yiyeceklerin füzyon mutfak uygulamalarına uygun olduğu belirtilmiştir. Turan vd., (2020)'nin çalışmasında da Çanakkale mutfağı örneğinin füzyon mutfak uygulamalarına uygun olduğu, Fransız ve İtalyan mutfaklarına ait ürünlerle yenilikçi füzyon ürünlerinin ortaya konulduğu tespit edilmiştir. Bu bağlamda, Türk mutfağı, Fransız mutfağı ve İtalyan mutfağ 1 ürünleri ile yeni bir füzyon mutfağı yaklaşımı ölçeği oluşturma bakımından bu çalışma önemlidir. Ayrıca, füzyon mutfağı uygulama yaklaşımları ile farklı mutfağa ait özellikleri tek bir tabakta yeni bir lezzette, renkte, aromada ve yapıda birleştirme açısından da önemli olduğu söylenebilir.

Bu çalışmanın amacı bireylerin füzyon mutfağı uygulamalarına yönelik olarak Türk mutfağı, Fransız mutfağı ve İtalyan mutfağına yaklaşımları ölçeğinin geçerlenmesine ilişkin faktör ve güvenirlik analizleri ile beraber şu sorulara cevap aranmıştır:

1. Bireylerin füzyon mutfağı uygulamalarına yaklaşım ölçeği alt boyutları ile demografik değişkenleri arasında fark var mıdır?

2. Bireylerin füzyon mutfağı uygulamalarına yaklaşım ölçeği alt boyutları ile yurt dışında bulunma ve yaş değişkenleri arasında fark var mıdır?

3. Bireylerin füzyon mutfağı uygulamalarına yaklaşım ölçeğinin alt boyutları arasında ilişki var midir?

\section{YÖNTEM}

\section{Evren ve Örneklem}

Bu çalışmanın örneklemini Ankara ili Kültür ve Turizm Bakanlığında çalışan 364.342 kamu personelinden kolaylıkla bulunabilen örnekleme ile araştırmaya gönüllü olan 110 kadın ve 147 erkek olmak üzere toplam 257 birey oluşturmuştur. Kolaylıkla bulunabilen örnekleme, bir bölge söz konusu değilse, yakın çevrede bulunan ve ulaşılması kolay, elde mevcut ve araştırmaya katılmak isteyen (gönüllü) bireyler üzerinde yapılan örneklemedir (Erkuş, 2013: 122). Bireylerin \%42.8'i kadın, \%57.2'si erkektir. Bunların \%7.8'i 18-22, \% 5.8'i 23-27, \% 11.3'ü 28-32, \% 75.1'i 33 ve üzeri yaş aralığındadır. Katılımcıların \% 33.1'inin yurtdışına seyahat etmediği, \% 66.9'unun yurtdışına seyahat ettiği belirlenmiştir. Yurtdışına seyahat edenlerin \% 41.3'ü 1-3 kez, \%25'i 4-6 kez, \%15.7'si 7-9 kez, \% 18'i 10 ve daha fazla kez seyahat ettiği belirlenmiştir. Katılımcıların \%80.6'sının sağlık problemi bulunmadığı, \%19.4'ünün ise sağlık problemi olduğu tespit edilmiştir.

\section{Veri Toplama Araçları}

Araştırma verilerinin toplanmasında "Demografik Bilgi Formu", "Füzyon Mutfağ1 Uygulamalarına Yaklaşım Formu" ve "Bireysel Yenilikçi Ölçeği" (BYÖ) kullanılmıştır.

\section{Demografik Bilgi Formu}

$\mathrm{Bu}$ formda, bireylerin cinsiyet, yaş, sağlık problemleri, yurtdışına gidiş durumlarına ilişkin sorular yer almaktadır. 


\section{Füzyon Mutfağı Uygulamalarına Yaklaşım Formu}

Araştırmacılar tarafından oluşturulan anket formu için öncelikle alanyazın taraması yapılmıştır (Castelman, 2003; Arslan, 2015; Sarışık, 2016:28; Y1ldız, 2016:27; Della, 2017; Bourdain, 2018:615; Guzek vd., 2019:2622; Lawrence, 2019; Köksal Sezgin, 2020). Bunun için Türk mutfağı, Fransız ve İtalyan mutfağı uygulamaları ile ilgili ifadeler üç mutfağı da temsil eden örnek yiyeceklerle, Guzek vd., (2019)'a göre de "başlangıçlar, çorbalar, ana yemekler, tatlılar" şeklinde belirlenmiştir. Öncellikle konu ile ilgili soru havuzu oluşturulmuş, formun kapsam geçerliliğinin sağlanması için bir beslenme ve iki gastronomi ve mutfak sanatları alan uzmanı olarak toplam üç uzmanın görüşüne sunulmuştur. Uzman önerilerine göre gerekli düzeltmeler yapılmıştır. Görüşme formundaki soruların anlaşılabilirliğini sağlamak için 50 maddeden oluşan formun, 86 bireye pilot uygulaması yapılmıştır. Ön uygulamada cevapları örtüşen sorular çıkarılarak formda 36 madde olarak son şekli verilmiştir.

"Füzyon Mutfağı Uygulamalarına Yaklaşım” formunda: Türk mutfağı, Fransız mutfağı ve İtalyan mutfağ yemeklerine ilişkin ifadelerden oluşan sorulara yer verilmiştir. Formda yer alan ifadeler başlangıçta 13 maddesi "yenilikçi", 8 maddesi "şüpheci" ve 15 maddesi "gelenekçi" olmak üzere üç alt boyutta ve toplam 36 madde olarak oluşturulmuştur. Her bir madde 1=Hiç katılmıyorum, 5=Tamamen katıllyorum arasında 5'li Likert tipi derecelendirme ile değerlendirilmiştir (Akbaş vd., 2020:222). Maddeler olumlu ve olumsuz ifadeler şeklinde düzenlenmiştir. Puanlamada olumsuz olan maddelerin puanlaması ters yapılmıştır.

Bireylerin "Füzyon Mutfağı Uygulamalarına Yaklaşım Ölçeğine" ilişkin güvenirlik ve geçerlik çalışmasının Cronbach Alpha değeri "yenilikçi" alt boyutunda 0.776, "şüpheci" alt boyutunda 0.704 ve "gelenekçi" alt boyutunda 0.748 olarak belirlenmiştir. Veri yapısının faktör analizi için uygunluğu Kaiser-Meyer Olkin (KMO) değeri 0.747 ve Bartlett küresellik testinde hesaplanan kikare değeri $\left(X^{2}=4411.007 ; p<0.000\right)$ bulunmuştur. Bu çalışma sonucunda KMO değerinin 0.74 'den yüksek olması ve Bartlett küresellik testinin anlamlı çıkması, bu çalışma için faktör analizinin yapılabileceğini göstermiştir (Büyüköztürk vd., 2012: 93).

\section{Bireysel Yenilikçilik Ölçeği (BYÖ)}

Kılıçer ve Odabaşı (2010) tarafından geliştirilen bireysel yenilikçi ölçeği 20 maddeden oluşmaktadır. Bireysel Yenilikçilik Ölçeğinde kullanılan, her bir madde 1=Katılmıyorum, 2=Biraz katılıyorum, 3=Orta düzeyde katılıyorum, 4=Çoğunlukla katılıyorum, 5=Tamamen katılıyorum arasında 5'li Likert tipi derecelendirme ile değerlendirilmiştir. Maddeler olumlu ifadeler şeklinde düzenlenmiştir. Madde puanlarının yüksek olması bilgi, tutum ve davranış alt boyutlarının olumlu yönde artış olduğunu ifade etmektedir. Öncellikle, ölçek hesaplama formülünde $=42+(1$, $2,3,5,8,9,11,12,14,16,18,19$.)- $(4,6,7,10,13,15,17$. ve 20.) maddelerin toplamı alınmıştır. Ölçekte 68-120 arası puan alanlar "yenilikçi", 68-64 arası puan alanlar "şüpheci", 64 altı puan alanlar "gelenekçi" olarak gruplanmıştır.

\section{Veri Toplama Süreci}

Verilerin toplanmasında yüz yüze anket tekniği uygulanmıştır. Bireylerin veri toplama aracına katılımları gönüllülük esasına dayandırılmıştır. Araştırmaya sadece gönüllü olan bireyler alınmıştır. Araştırma T.C. Kültür ve Turizm Bakanlığı'nda uygulanmıştır. Veri toplama aracının uygulamasının yapılabilmesi için Bakanlık yetkililerinden izin alınmıştır. Veriler araştırmacılar tarafından uygulanmıştır. Bireylerin veri toplama aracını cevaplama süreleri 30 dakika sürmüştür. 


\section{İstatistiksel Analizler}

Verilerin çözümlenmesinde SPSS 16.0 paket programından yararlanılmıştır. Yetişkinlerin Türk mutfağında füzyon uygulamalarına yaklaşımı ölçeğine ilişkin geçerlik ve güvenirlik analizi yapılmıştır. Bu ölçekteki alt boyutlar ile kişisel değişkenler arasındaki farklılığın incelenmesi için t-testi kullanılmıştır. Yetişkinlerin Türk mutfağında füzyon uygulamalarına yaklaşımı ölçeğindeki alt boyutlar ile kişisel değişkenler arasındaki farklılığın incelenmesi için ANOVA (One-way) testi kullanılmıştır. Türk mutfağında füzyon uygulamalarına yaklaşımı ölçeğinin alt boyutları arasındaki ilişkinin incelenmesi için regrasyon analizi yapılmıştır.

\section{BULGULAR}

Türk mutfağında füzyon uygulamalarına yaklaşım ölçeği verilerinin yapı geçerliliği açıklayıcı faktör analizi (EFA) ile belirlenmeye çalışılmıştır. Ölçeğin birbirinden bağımsız alt faktörlerini belirlemek için principal compenent analysis (PCA) varimax yöntemi kullanılmıştır. Faktör yükü 0.32 'nin üstünde olan ve eigen değeri 1.00 'den büyük olan maddeler ölçeğe alınmıştır. EFA ile ölçeğin üç faktörlü yapısı desteklenmiş 54 madde olarak düzenlenmiş olan ölçme aracı 36 maddeye inmiştir. Tablo $1-4$ 'de füzyon mutfağı uygulamalarına ait analizi sonuçları bulunmaktadır.

Tablo 1'de "füzyon mutfağ1 uygulamalarına yaklaşım ölçeği" ne ilişkin geçerlik ve güvenirlik sonuçları 36 maddenin üç alt boyutundan oluşmaktadır. Alt boyutların iç tutarlılık katsayısı Cronbach Alpha ile belirlenmiş olup; "yenilikçi" alt boyutunda yer alan madde yükleri 0.3320.664 arasında, "şüpheci" alt boyutunda yer alan madde yükü 0.419- 0.764 arasında, "gelenekçi" alt boyutunda yer alan madde yükü 0.303-0.729 arasında olduğu tespit edilmiştir.

Bu üç faktör toplam varyansın \%73.006'sını açıklamaktadır. Faktörlerin döndürme sonrasında açıladıkları varyanslara bakıldığında, "yenilikçi" faktörün \%33.44 "şüpheci" faktörün varyansı \% 19.80 ve "gelenekçi" faktörü \% 19.75 olarak tespit edilmiştir.

Alt boyutların iç tutarlılık katsayısı Cronbach Alpha ile belirlenmiş olup; "yenilikçi" alt boyutu 0.776, "şüpheci" alt boyutu 0.704 ve alt "gelenekçi" boyutu 0.748 'dür. Ölçeğin genel Alpha güvenirlik katsayısı $0.778^{\prime}$ dir. Veri yapısının faktör analizi için uygunluğu Kaiser-Meyer Olkin $(K M O)$ değeri 0.747 ve Bartlett küresellik testinde hesaplanan ki-kare değeri $\left(X^{2}=4411.007\right.$; $\mathrm{p}<0.000$ ) olarak bulunmuştur. Bu çalışma sonucunda KMO değerinin 0.70 'ten yüksek olması ve Bartlett küresellik testinin anlamlı çıkması, bu çalışma için faktör analizinin yapılabileceğini göstermiştir (Büyüköztürk vd., 2012). Alpha güvenirlik katsayısının değerlendirilmesinde uyulan değerlendirme kriterleri göz önüne alındığında ölçeğin kabul edilebilir güvenirlik katsayısına sahip olduğu bulunmuştur (Özdamar, 1999). 
Tablo 1. Füyon Mutfağı Uygulamalarına Yaklaşım Ölçeğine İlişkin Faktör Analizi ve Güvenlik Analizi Sonuçları

\begin{tabular}{|c|c|c|c|c|}
\hline Madde & İfadeler & Yenilikçi & Şüpheci & Gelenekçi \\
\hline 1. & Beşamel soslu sucuk köftesini tadarım & 0.332 & & \\
\hline 2. & Kars gravyerli soğan çorbası tadarım & 0.360 & & \\
\hline 3. & Pesto soslu erişte tadarım & 0.426 & & \\
\hline 4. & Dört mevsim pizza tadarım & 0.466 & & \\
\hline 5. & Napolitan soslu ızgara böbrek tadarım & 0.500 & & \\
\hline 6. & $\begin{array}{l}\text { Kızarmış sarımsaklı mısır ekmeği üzerine dana steak tartar } \\
\text { tadarım }\end{array}$ & 0.500 & & \\
\hline 7. & Beşamel soslu beyti tadarım & 0.505 & & \\
\hline 8. & Kızarmış lavaş üzerinde kaz ciğeri tadarım & 0.509 & & \\
\hline 9. & Haşhaşlı otlu krep tadarım & 0.511 & & \\
\hline 10. & Tahinli galetta tadarım & 0.517 & & \\
\hline 11. & Antep fistıklı mus tadarım & 0.593 & & \\
\hline 12. & Kuru meyvelerle hazırlanmış biscotti tadarım & 0.616 & & \\
\hline 13. & Erzincan tulum peynirli ravioli tadarım & 0.664 & & \\
\hline 14. & Acuka soslu bruschetta tatmam & & 0.419 & \\
\hline 15. & Asma yaprağına kapari soslu kılıç balığı tatmam & & 0.422 & \\
\hline 16. & Pastırmalı cordon bleu tatmam & & 0.488 & \\
\hline 17. & Pekmezle marine edilmiş ördek confit tatmam. & & 0.650 & \\
\hline 18. & $\begin{array}{l}\text { Bruschetta ekmek üzeri peynir ve sebze karışımından } \\
\text { yapılan soğuk sandviçi tatmam }\end{array}$ & & 0.650 & \\
\hline 19. & Tortellini sebze sularından hazırlanan erişteyi tatmam & & 0.707 & \\
\hline 20. & Parmesanlı tarhana çorbası tatmam & & 0.742 & \\
\hline 21. & Otlu peynirli Napoli pizzayı tatmam & & 0.764 & \\
\hline 22. & Risottolu mumbar dolmasinı tatmam & & & 0.303 \\
\hline 23. & $\begin{array}{l}\text { Devekuşu yumurtası ile hazırlanmış sebzeli Frittata } \\
\text { (İtalyan omleti) tatmam }\end{array}$ & & & 0.382 \\
\hline 24. & Chianti şarabı ile marine edilmiş kuzu şiş tatmam & & & 0.484 \\
\hline 25. & Lor peynirli cannoli tatlısı tatmam & & & 0.515 \\
\hline 26. & Pastırmalı Croque Madam tatmam & & & 0.530 \\
\hline 27. & Kurbağa bacağı buğulama tatmam & & & 0.540 \\
\hline 28. & İç pilavlı escargots (salyangoz) tatmam & & & 0.566 \\
\hline 29. & Köri soslu Adana şişi tatmam & & & 0.569 \\
\hline 30. & $\begin{array}{l}\text { Maraş kesme dondurma eşliğinde Bursa şeftalisinden } \\
\text { hazırlanan Peach Melba tatmam }\end{array}$ & & & 0.574 \\
\hline 31. & Siyez unlu ekşi mayalı baget ekmem tedarım & & & 0.618 \\
\hline 32. & Maraş biberli domates soslu ratatouille tatmam & & & 0.633 \\
\hline 33. & Pekmezli Panna Cotta tatlısını tatmam & & & 0.660 \\
\hline 34. & Patlıcan beğendili sufleyi tatmam & & & 0.676 \\
\hline 35. & Eski kaşar kullanarak hazırlanan dana Carpaccio tatmam & & & 0.723 \\
\hline 36. & Kokoreçli lazanya tatmam & & & 0.729 \\
\hline \multirow{6}{*}{\multicolumn{2}{|c|}{$\begin{array}{l}\text { Özdeğerler (eigenvalues) } \\
\text { Varyansı açılama oranı } \\
\text { Kümülatif varyans } \\
\text { Alt Boyut Güvenirliği (Cronbach's Alpha) } \\
\text { Genel Ölçek Güvenirliği (Cronbach's Alpha) }\end{array}$}} & 6.354 & 3.763 & 3.753 \\
\hline & & 33.444 & 19.808 & 19.754 \\
\hline & & $\% 33.444$ & $\%$ & $\% 73.006$ \\
\hline & & & 53.252 & \\
\hline & & 0.776 & 0.704 & 0.748 \\
\hline & & & 0.778 & \\
\hline
\end{tabular}

Kaiser-Meyer-Olkin $(K M O)=0.747 \quad$ Bartlett testi: $\chi^{2}=4411.007 ; p<0.000$ 
Tablo 2. Füzyon Mutfağı Uygulamalarına Yaklaşımın Alt Boyutlar ile Demografik Değişkenler Arasındaki Farklılığın Analizi (T-Testi) N=257

\begin{tabular}{|c|c|c|c|c|c|c|c|}
\hline Boyutlar & Değişkenler & Gruplar & $\mathbf{N}$ & $\overline{\mathrm{X}}$ & SD & $\mathbf{t}^{*}$ & $\mathbf{p}$ \\
\hline \multirow{6}{*}{ Yenilikçi } & \multirow{2}{*}{ Cinsiyet } & Kadın & 110 & 2.89 & 0.47 & \multirow{2}{*}{--4.013} & \multirow{2}{*}{0.000} \\
\hline & & Erkek & 147 & 3.19 & 0.67 & & \\
\hline & \multirow{2}{*}{ Sağlık problemi } & Evet & 50 & 2.96 & 0.61 & \multirow{2}{*}{-1.346} & \multirow{2}{*}{0.179} \\
\hline & & Hayır & 207 & 3.09 & 0.61 & & \\
\hline & \multirow{2}{*}{ Yurtdışı deneyimi } & Evet & 172 & 2.97 & 0.52 & \multirow{2}{*}{-3.570} & \multirow{2}{*}{0.000} \\
\hline & & Hayır & 85 & 3.25 & 0.72 & & \\
\hline \multirow{6}{*}{ Şüpheci } & \multirow{2}{*}{ Cinsiyet } & Kadın & 110 & 3.82 & 0.65 & \multirow{2}{*}{-2.010} & \multirow{2}{*}{0.046} \\
\hline & & Erkek & 147 & 3.63 & 0.80 & & \\
\hline & \multirow{2}{*}{ Sağlık problemi } & Evet & 50 & 3.89 & 0.73 & \multirow{2}{*}{-1.923} & \multirow{2}{*}{0.056} \\
\hline & & Hayır & 207 & 3.67 & 0.74 & & \\
\hline & \multirow{2}{*}{ Yurtdışı deneyimi } & Evet & 172 & 3.64 & 0.76 & \multirow{2}{*}{-2.145} & \multirow{2}{*}{0.033} \\
\hline & & Hayır & 85 & 3.85 & 0.69 & & \\
\hline \multirow{6}{*}{ Gelenekçi } & \multirow{2}{*}{ Cinsiyet } & Kadın & 110 & 2.50 & 0.34 & \multirow{2}{*}{--4.131} & \multirow{2}{*}{0.000} \\
\hline & & Erkek & 147 & 2.83 & 0.77 & & \\
\hline & \multirow{2}{*}{ Sağlık problemi } & Evet & 50 & 2.63 & 0.41 & \multirow{2}{*}{-0.709} & \multirow{2}{*}{0.479} \\
\hline & & Hayır & 207 & 2.70 & 0.69 & & \\
\hline & \multirow{2}{*}{ Yurtdışı deneyimi } & Evet & 172 & 2.58 & 0.51 & \multirow{2}{*}{--4.079} & \multirow{2}{*}{0.000} \\
\hline & & Hayır & 85 & 2.92 & 0.81 & & \\
\hline
\end{tabular}

${ }^{*}$ Independent sample t-test. M: Mean; SD: Standard deviation

Tablo 2' de Türk mutfağında füzyon uygulamalarına yaklaşım ölçeğinin "yenilikçi” alt boyutu ile cinsiyet değişkenine göre incelendiğinde, Türk mutfağında füzyon uygulamalarına yaklaşım ölçeğinin "Haşhaşlı otlu krep tadarım", "Tahinli galetta tadarım", "Kuru meyvelerle hazırlanmış biscotti tadarım" gibi ifadelerden oluşan "yenilikçi" alt boyutu ile cinsiyet değişkenine göre, kadınların puan ortalaması $(M=2.89)$ düşük iken, erkeklerin puan ortalamasının $(M=3.19)$ yüksek olduğu tespit edilmiştir. Cinsiyet değişkenine göre füzyon uygulamaları yaklaşım ölçeğinin "yenilikçi" alt boyut ile karşılaştırıldığında gruplar arasında istatistiksel olarak anlamlı fark bulunmuştur $(\mathrm{p}<0.05)$.

Türk mutfağında füzyon uygulamalarına yaklaşım ölçeğinin "Beşamel soslu sucuk köftesini tadarım", "Dört mevsim pizza tadarım", "Pesto soslu erişte tadarım" gibi ifadelerden oluşan "yenilikçi" alt boyutuna göre, Türk mutfağında füzyon uygulamaları ölçeğinin "yenilikçi" alt boyutuna göre, sağlık problemi olmayan bireylerin puan ortalaması $(M=2.96)$ düşük iken, sağlık problemi olmayan bireylerin puan ortalamasının $(M=3.09)$ yüksek olduğu ifade edilmiştir. Sağlık problemi 
değişkenine göre füzyon mutfağı uygulamaları yaklaşım ölçeğinde "yenilikçi" alt boyut ile karşılaştırıldığında gruplar arasında istatistiksel olarak anlamsız fark tespit edilmiştir ( $p>0.05)$.

Türk mutfağında füzyon uygulamalarına yaklaşım ölçeğinin "yenilikçi" alt boyutu ile yurtdışı seyahat değişkenine göre, yurtdışı deneyimi olanların puan ortalaması $(M=2.97)$ düşük iken, yurtdışı deneyimi olmayanların puan ortalamasının $(M=3.25)$ yüksek olduğu saptanmıştır. Yurtdışı deneyimi değişkenine göre füzyon mutfağı uygulamaları ölçeğinde "yenilikçi” alt boyut ile karşılaştırıldığında gruplar arasında istatistiksel olarak anlamlı fark tespit edilmiştir $(\mathrm{p}<0.05)$.

Türk mutfağında füzyon uygulamalarına yaklaşım ölçeğinin "şüpheci" alt boyutu cinsiyet değişkenine göre incelendiğinde, Türk mutfağında füzyon uygulamaları ölçeğinin "Pekmezle marine edilmiş ördek confit tatmam", "Pastırmalı cordon bleu tatmam", "Otlu peynirli Napoli pizzayı tatmam" gibi ifadelerden oluşan "şüpheci" alt boyutu cinsiyet değişkenine göre incelendiğinde, kadınların puan ortalaması $(M=3.82)$ yüksek iken, erkeklerin puan ortalamasının $(M=3.63)$ düşük olduğu bulunmuştur. Cinsiyet değişkenine göre füzyon mutfağı uygulamaları yaklaşım ölçeğinde "şüpheci" alt boyut ile karşılaştırıldığında gruplar arasında istatistiksel olarak anlamlı fark belirlenmiştir $(\mathrm{p}<0.05)$.

"Şüpheci" alt boyuta göre, sağlık problemi olduğunu belirten bireylerin puan ortalaması $(M=3.89)$ yüksek iken, sağlık problemi olmayanların puan ortalamasının $(M=3.67)$ düşük olduğu saptanmıştır. Sağlık problemi değişkenine göre füzyon mutfağı uygulamaları ölçeğinde "şüpheci" alt boyut ile karşılaştırıldığında gruplar arasında istatistiksel olarak anlamsız fark tespit edilmiştir ( $\mathrm{p}>0.05)$.

Türk mutfağında füzyon uygulamalarına yaklaşım ölçeğinin "şüpheci" alt boyutu ile yurtdışı deneyimi değişkenine göre incelendiğinde, yurt dışı deneyimi olan bireylerin puan ortalaması $(M=3.64)$ düşük iken, yurtdışı deneyimi olmayanların puan ortalamasının $(M=3.85)$ yüksek olduğu saptanmıştır. Yurt dışı deneyim değişkenine göre füzyon mutfağı uygulamaları yaklaşım ölçeğinde "şüpheci" alt boyut ile karşılaştırıldığında gruplar arasında istatistiksel olarak anlamlı fark bulunmuştur $(\mathrm{p}<0.05)$.

Türk mutfağında füzyon uygulamalarına yaklaşım ölçeğinin "Devekuşu yumurtası ile hazırlanmış sebzeli Frittata (İtalyan omleti) tatmam", "Chianti şarabı ile marine edilmiş kuzu şiş tatmam", "İç pilavlı escargots (salyangoz) tatmam" gibi ifadelerden oluşan "gelenekçi" alt boyutu cinsiyet değişkenine göre incelendiğinde, kadınların puan ortalaması $(M=2.50)$ düşük iken, erkeklerin puan ortalamasının $(M=2.83)$ yüksek olduğu bulunmuştur. Cinsiyet değişkenine göre füzyon mutfağ uygulamaları yaklaşım ölçeğinde "gelenekçi" alt boyut ile karşılaştırıldığında gruplar arasında istatistiksel olarak anlamlı fark tespit edilmiştir $(\mathrm{p}<0.05)$.

Türk mutfağında füzyon uygulamalarına yaklaşım ölçeğinin "gelenekçi" alt boyutu ile sağlık problemi değişkenine göre, sağlık problemi olanların puan ortalaması $(M=2.63)$ düşük iken, sağlık problemi olmayanların puan ortalaması $(M=2.70)$ yüksek olduğu saptanmıştır. Sağlık problemi değişkenine göre füzyon mutfağı uygulamaları yaklaşım ölçeğinde "gelenekçi" alt boyut ile karşılaştırıldığında gruplar arasında istatistiksel olarak anlamsız fark tespit edilmiştir ( $p>0.05)$.

Türk mutfağında füzyon uygulamalarına yaklaşım ölçeğinin "gelenekçi" alt boyutu ile yurtdışı deneyimi olan bireylerin puan ortalaması $(M=2.58)$ düşük iken, yurtdışı deneyimi olmayan bireylerin puan ortalaması $(M=2.92)$ yüksek olduğu saptanmıştır. Yurtdışı deneyimine göre füzyon mutfağı uygulamaları yaklaşım ölçeğinde "gelenekçi" alt boyut ile karşılaştırıldığında gruplar arasında istatistiksel olarak anlamlı fark tespit edilmiştir $(\mathrm{p}<0.05)$. 
Tablo 3. Füzyon Mutfağı Uygulamalarına Yaklaşım Ölçeğinin Alt Boyutları ile Demografik Değişkenler Arasındaki Farklılık Analizi Sonuçları

\begin{tabular}{|c|c|c|c|c|c|c|c|c|}
\hline Boyutlar & Değişkenler & Gruplar & $\mathbf{N}$ & $\overline{\bar{X}}$ & SD & $\mathrm{F}^{*}$ & p & Tukey \\
\hline \multirow{8}{*}{ Yenilikçi } & \multirow{4}{*}{$\begin{array}{l}\text { Yaş } \\
(\mathrm{N}=257)\end{array}$} & 1 & 20 & 3.26 & 0.81 & \multirow{4}{*}{-10.630} & \multirow{4}{*}{0.000} & \multirow{4}{*}{$2-1,3,4$} \\
\hline & & 2 & 15 & 3.82 & 0.73 & & & \\
\hline & & 3 & 29 & 3.09 & 0.61 & & & \\
\hline & & 4 & 193 & 2.98 & 0.53 & & & \\
\hline & \multirow{4}{*}{$\begin{array}{l}\text { Bir yıl içinde } \\
\text { yurtdışına } \\
\text { çıkma sıklığ } 1 \\
(\mathrm{~N}=172)\end{array}$} & $1-3$ & 71 & 2.91 & 0.46 & \multirow{4}{*}{0.643} & \multirow{4}{*}{0.610} & \multirow{4}{*}{--} \\
\hline & & $4-6$ & 43 & 2.99 & 0.66 & & & \\
\hline & & $7-9$ & 27 & 3.05 & 0.39 & & & \\
\hline & & 10 ve daha fazla & 31 & 3.01 & 0.54 & & & \\
\hline \multirow{8}{*}{ Şüpheci } & \multirow{4}{*}{$\begin{array}{l}\text { Yaş } \\
(\mathrm{N}=257)\end{array}$} & $18-22$ & 20 & 3.49 & 0.89 & \multirow{4}{*}{1.092} & \multirow{4}{*}{0.400} & \multirow{4}{*}{-- } \\
\hline & & $23-27$ & 15 & 3.91 & 0.69 & & & \\
\hline & & $28-32$ & 29 & 3.64 & 0.64 & & & \\
\hline & & 33 ve üzeri & 194 & 3.73 & 0.74 & & & \\
\hline & \multirow{4}{*}{$\begin{array}{l}\text { Bir yıl içinde } \\
\text { yurtdışına } \\
\text { çıkma sıklığı } \\
(\mathrm{N}=172)\end{array}$} & $1-3$ & 71 & 3.72 & 0.72 & \multirow{4}{*}{0.799} & \multirow{4}{*}{0.580} & \multirow{4}{*}{--} \\
\hline & & 4- 6 & 43 & 3.67 & 0.72 & & & \\
\hline & & 7-9 & 27 & 3.53 & 0.68 & & & \\
\hline & & 10 ve daha fazla & 31 & 3.51 & 0.94 & & & \\
\hline \multirow{8}{*}{ Gelenekçi } & \multirow{4}{*}{$\begin{array}{l}\text { Yaş } \\
(\mathrm{N}=257)\end{array}$} & $18-22$ & 20 & 2.64 & 0.92 & \multirow{4}{*}{2.565} & \multirow{4}{*}{0.051} & \multirow{4}{*}{--} \\
\hline & & $23-27$ & 15 & 2.87 & 1.15 & & & \\
\hline & & $28-32$ & 29 & 2.96 & 0.78 & & & \\
\hline & & 33 ve üzeri & 193 & 2.64 & 0.51 & & & \\
\hline & \multirow{4}{*}{$\begin{array}{l}\text { Bir yıl içinde } \\
\text { yurtdışına } \\
\text { çıkma sıklığ } 1 \\
(\mathrm{~N}=172)\end{array}$} & $1-3$ & 71 & 2.62 & 0.51 & \multirow{4}{*}{0.925} & \multirow{4}{*}{0.43} & \multirow{4}{*}{-- } \\
\hline & & 4- 6 & 43 & 2.63 & 0.55 & & & \\
\hline & & 7-9 & 27 & 2.46 & 0.35 & & & \\
\hline & & 10 ve daha fazla & 31 & 2.50 & 0.56 & & & \\
\hline
\end{tabular}

*One-way ANOVA. M: Mean; SD: Standard sapma;

Yaş gruplama $1=18-22 ; 2=23-27 ; 3=28-32 ; 4=33$ ve üzeri

Tablo 3'te Türk mutfağında füzyon uygulamalarına yaklaşım ölçeğinin "yenilikçi" alt boyutu ile yaş grupları incelendiğinde, 33 ve üzeri yaş grubu puan ort. ( $M=2.98)$ düşük iken, 23-27 yaş grubu puan ort. ( $M=3.82)$ yüksek olduğu belirlenmiştir. Füzyon mutfağı uygulamaları yaklaşım ölçeğinin "yenilikçi" alt boyutu ile yaş grupları karşılaştırıldığında Tukey HSD Post-Hoc testiyle gruplar arasında istatistiksel olarak anlamlı fark tespit edilmiştir [ $F=10.630],(p<0.05)$.

Türk mutfağında füzyon uygulamalarına yaklaşım ölçeğinin "yenilikçi" alt boyutu ile bir yıl içinde yurt dışına çıkma sıklığı değişkeni incelendiğinde, bir yılda 1-3 arası yurt dışına çıkma sıklığı olanların puan ort. ( $M=2.91)$ düşük iken, 7-9 kez yurt dışına çıkma sıklığı olanların puan ort. ( $M=3.05)$ yüksek olduğu saptanmıştır. Füzyon mutfağı uygulamaları yaklaşım ölçeğinin 
"yenilikçi" alt boyutu ile bir yılda yurt dışına çıkma sıklığı grupları karşılaştırıldığında Tukey HSD Post-Hoc testiyle gruplar arasında istatistiksel olarak anlamsız fark tespit edilmiştir [F= 0.643], $(\mathrm{p}>0.05)$.

Türk mutfağında füzyon uygulamalarına yaklaşım ölçeğinin "şüpheci" alt boyutu ile yaş grupları incelendiğinde, 18-22 yaş grubu puan ort. $(M=3.49)$ düşük iken, 23-27 yaş grubu puan ort. $(M=3.91)$ yüksek olduğu belirlenmiştir. Füzyon mutfağı uygulamaları yaklaşım ölçeğinin "şüpheci" alt boyutu ile yaş grupları karşılaştırıldığında Tukey HSD Post-Hoc testiyle gruplar arasında istatistiksel olarak anlamlı fark tespit edilmiştir [F=1.092], ( $\mathrm{p}>0.05)$.

Türk mutfağında füzyon uygulamalarına yaklaşım ölçeğinin "şüpheci" alt boyutu ile bir yıl içinde yurt dışına çıkma sıklığı değişkeni incelendiğinde, bir yılda 10 ve üzeri yurt dişına çıkma sıklığ olanların puan ort. $(M=3.51)$ düşük iken, $1-3$ kez yurt dışına çıkma sıklığı olanların puan ort. $(M=3.72)$ yüksek olduğu saptanmıştır. Füzyon mutfağı uygulamaları yaklaşım ölçeğinin "şüpheci" alt boyutu ile bir yılda yurt dışına çıma sıklığı grupları karşılaştırıldığında Tukey HSD Post-Hoc testiyle gruplar arasında istatistiksel olarak anlamsız fark tespit edilmiştir [ $F=0.799$ ], $(\mathrm{p}>0.05)$.

Türk mutfağında füzyon uygulamalarına yaklaşım ölçeğinin "gelenekçi" alt boyutu ile yaş grupları incelendiğinde, hem 18-22 yaş grubu puan ort. $(M=2.64)$ düşük olduğu hem de 33 ve üzeri yaş grubu puan ort. $(M=2.64)$ düşük olduğu saptanmıştır. Füzyon mutfağı uygulamaları yaklaşım ölçeğinin gelenekçi alt boyutu ile yaş grupları karşılaştırıldığında Tukey HSD Post-Hoc testiyle gruplar arasında istatistiksel olarak anlamlı fark tespit edilmiştir [ $F=2.565],(p>0.05)$.

Türk mutfağında füzyon uygulamalarına yaklaşım ölçeğinin "gelenekçi" alt boyutu ile bir yıl içinde yurt dışına çıkma sıklığı değişkeni incelendiğinde, bir yılda 7-9 arası yurt dışına çıma sıklığı olanların puan ort. $(M=2.46)$ düşük iken, 4-6 kez yurt dişına çıkanların puan ort. $(M=2.63)$ yüksek olduğu saptanmıştır. Füzyon mutfağı uygulamaları yaklaşım ölçeğinin "gelenekçi" alt boyutu ile bir yılda yurt dişına çıkma sıklığı grupları karşılaştırıldığında Tukey HSD Post-Hoc testiyle gruplar arasında istatistiksel olarak anlamsız fark tespit edilmiştir [F=0.925], ( $\mathrm{p}>0.05)$.

Tablo 4. Füzyon mutfağı uygulamalarına yaklaşım ölçeğinin alt boyutları arasındaki ilişkinin regrasyon sonuçları

\begin{tabular}{|c|c|c|c|c|c|}
\hline Boyutlar & & Top FMUYÖ & Yenilikçi & Şüpheci & Gelenekçi \\
\hline \multirow[b]{2}{*}{ Top FMUYÖ } & $\mathrm{r}$ & & 0.131 & 0.358 & 0.288 \\
\hline & $p$ & 1 & $0.036^{*}$ & $0.000^{* *}$ & $0.000^{* *}$ \\
\hline \multirow[b]{2}{*}{ Yenilikçi } & $\mathrm{r}$ & & & -0.079 & 0.389 \\
\hline & $\mathrm{p}$ & & 1 & 0.207 & $0.000^{* *}$ \\
\hline \multirow[b]{2}{*}{ Şüpheci } & $\mathrm{r}$ & & & & 0.214 \\
\hline & $\mathrm{p}$ & & & 1 & $0.001^{* *}$ \\
\hline \multirow[b]{2}{*}{ Gelenekçi } & $\mathrm{r}$ & & & & \\
\hline & $\mathrm{p}$ & & & & 1 \\
\hline
\end{tabular}

${ }^{*} \mathrm{p}<0.05 ;{ }^{* *} \mathrm{p}<0.01$

Tablo 4'de Türk mutfağında füzyon uygulamalarına yaklaşım ölçeğinin "şüpheci" ( $\mathrm{r}=0.126)$ ve "yenilikçi" ( $\mathrm{r}=0.381)$ alt boyutu arasında pozitif yönde, "gelenekçi" $(\mathrm{r}=-0.332)$ alt boyutunda ise negatif yönde ilişki bulunmuştur. Türk mutfağında füzyon uygulamalarına yaklaşım ölçeğinin alt boyutları ile bireysel yenilikçi ölçeğinin alt boyutları karşılaştırıldığında gruplar arasında istatistiksel olarak anlamlı fark tespit edilmiştir $(\mathrm{p}<0.05, \mathrm{p}<0.01)$. 


\section{TARTIŞMA, SONUÇ ve ÖNERILLER}

Bu çalışmada füzyon mutfağı uygulamalarına yönelik olarak Türk mutfağı, Fransız mutfağı ve İtalyan mutfağına yaklaşım ölçeğinin geçerlenmesi planlanmıştır. Ölçme aracının birbirinden bağımsız alt faktörlerini belirlemek için Principal Compenent Analysis (PCA) Varimax yöntemi kullanılmıştır. Faktör yükü 0.32 'nin üstünde olan ve eigen değeri 1.00 'den büyük olan maddeler ölçeğe alınmıştır. Füzyon uygulamalarına yaklaşım ölçeğinin açıklayıcı faktör analizi (EFA) ve Alpha kat sayısı sonuçları, aracın geçerlik ve güvenirlik katsayısının uygun olduğu tespit edilmiştir.

Türk mutfağında füzyon uygulamalarına yaklaşım ölçeğinin "Haşhaşlı otlu krep tadarım", "Tahinli galetta tadarım", "Kuru meyvelerle hazırlanmış biscotti tadarım" gibi ifadelerden oluşan "yenilikçi" alt boyutu ile cinsiyet değişkenine göre, erkeklerin kadınlara göre daha "yenilikçi" olduğu tespit edilmiştir. Bu çalışma ile genellenemez ancak erkeklerin umami tatlara, lezzetlere ve farklı kültür yemeklerine açı olmalarından kaynaklı olduğu düşünülebilir. Başka çalışmalarda ise bireylerin yeni yiyeceklere yaklaşımlarında cinsiyet faktörünün anlamlı bir farklılık oluşturmadığ saptanmıştır (Yiğit, 2018). Wright vd., (2001) ve Reed vd., (2006) tarafından yapılan çalışmalarda cinsiyetin ve kültürel nedenlerin etkisi olsa da yiyecekteki umami tadın keskin aroması, ekşiliği, tatlılığın, tuzun yiyecekteki kokudan daha az önemli olduğu, Del Moral (2020)'a göre ise Asya ve Doğu kültürü mutfağında umami tatlar tercih edilmezken, İtalyan mutfağında keskin tatların, aromaların daha çok tercih edildiği belirtilmiştir.

Türk mutfağında füzyon uygulamalarına yaklaşım ölçeğinin "Beşamel soslu sucuk köftesini tadarım", "Dört mevsim pizza tadarım", "Pesto soslu erişte tadarım" gibi ifadelerden oluşan "yenilikçi" alt boyutuna göre, sağlık problemi olmayan bireylerin sağlık problemi olan bireylere göre yeni lezzetleri tatma konusunda daha yenilikçi olduğu ifade edilmiştir. Bu durumun, füzyon mutfağ uygulamalarında üretilen yeni ürünler ile hem daha sağlıklı atıştırmalıklar hem de daha görselde yenilikçi sunumlar oluşturulabileceği söylenebilir. Spence (2017)'e göre yeni oluşturulan füzyon yemeklerinin genellikle iyi hissetmek için yenilen yeni macera yüklü duygular ile yenildiği için daha sağlığa faydalı olabileceği ifade edilmiştir.

Türk mutfağında füzyon uygulamalarına yaklaşım ölçeğinin "Pekmezle marine edilmiş ördek confit tatmam", "Pastırmalı cordon bleu tatmam", "Otlu peynirli Napoli pizzayı tatmam" gibi ifadelerden oluşan "şüpheci" alt boyutu cinsiyet değişkenine göre incelendiğinde, kadınların erkeklere göre daha şüpheci yaklaşım içinde olduğu bulunmuştur. Bu durum kadınların erkeklere göre füzyon mutfağının "Türk mutfağı" kültürüne uzak olması ve/veya ürün hazırlama maliyetinin yüksek olması nedeniyle şüpheci bir davranış göstermiş olabilir. Olabi vd., (2015) tarafından yapılan çalışmada yeni yiyeceklere karşı olan yaklaşımlarında kadınlar ile erkekler arasında neofobi düzeylerinde anlamsız fark olduğu saptanmıştır.

Türk mutfağında füzyon uygulamalarına yaklaşım ölçeğinin "şüpheci" alt boyut, sağlık problemi değişkenine göre incelendiğinde, sağlik problemi olmayan bireylerin, sağlık problemi olan bireylere göre füzyon mutfağı ürünlerine daha şüpheci yaklaştıkları saptanmıştır. Bu durum, bireylerin sağlığına zarar verecek kaygısıyla yeniliklere daha endişeli yaklaştıkları söylenebilir. Tupini (2016)'ye göre yeni gastronomik deneyimler oluşturmak etnik ve ekzotik mutfakların büyümesine neden olurken, yeni mutfaklara yaklaşımlarında bireylerin sağlığına zarar verir korkusuyla şüpheci yaklaşımlarına neden olmuştur. Spence (2018)'de füzyon mutfağındaki şüpheciliği ortadan kaldırmada en çok Michelin şefleri rehberliğinde bazı lüks mutfaklar ile lüks restoranların artmasına Çin, Japon, Meksika ve Peru mutfaklarının sağlıklı ürünler hazırlandığı bilgisine geçilmiştir.

Türk mutfağında füzyon uygulamalarına yaklaşım ölçeğinin "şüpheci" alt boyutu ile yurtdışı deneyimi değişkenine göre incelendiğinde, yurtdışı deneyimi olmayan bireylerin yurt dışı 
deneyimi olan bireylere göre füzyon mutfağı uygulamalarında elde edilen yeni ürünlere daha şüpheci yaklaştıkları ifade edilebilir. Bu durum, bireylerin daha önce yurt dışına gitmediği için füzyon mutfağı uygulamalarına önyargılı yaklaşımlarından kaynaklı olabilir. Spence (2018)'e göre, menüdeki yemek isimleri örneğin, Parmesanlı dondurma, yumurtalı dondurma gibi oluşturulan füzyon mutfağı uygulamaları ilk kez duyulduğu için şüpheci yaklaşım sergileyebilecekleri belirtilmiştir. Ancak, Privitera vd., (2018)'a göre ülkelerin mutfak uygulamaları, yurt dışı deneyimleri ve bölgesel koşulların kültürel etkisi olarak büyüyen gıda ve yerel yiyecek kültüründen kaynaklı şüpheli yaklaşılsa da zamanla oluşan aşinalık füzyon mutfağı ürünlerinin tüketiminde artış olduğu belirtilmiştir.

Türk mutfağında füzyon uygulamalarına yaklaşım ölçeğinin "Devekuşu yumurtası ile hazırlanmış sebzeli Frittata (İtalyan omleti) tatmam", "Chianti şarabr ile marine edilmiş kuzu şiş tatmam", "İç pilavl escargots (salyangoz) tatmam" gibi ifadelerden oluşan "gelenekçi" alt boyutu cinsiyet değişkenine göre incelendiğinde, kadınların erkeklere göre daha az gelenekçi olduğu bulunmuştur. Bu durum, füzyon mutfağı uygulamalarında oluşturulan ürünlerle ilgili cinsiyete göre bir genelleme yapılamaz. Ancak, kadınların aile bireyleri ve çocukların sağlıklı beslenmesi için farklı yemek uygulamalarının daha fazla olması nedeniyle yeni mutfaklardan olan füzyon mutfağına ilgilerinin arttı̆̆ düşünülebilir. Ancak Field ve Smith (2001) ve Geiling (2013)'e göre bazen kökenini yanlış bildiğimiz için gelenekçi davranış gösterebildiği şeylerin zamanla doğru olarak karşımıza çıkması bizi o ürünü daha çok tüketmemize neden olmaktadır. Örnek: Blake (2017)'ya göre IKEA'da İsveç köftesi olarak bilinen köfte toplarının, kökenin aslında bir Türk yemeği olduğu, ortaya çııınca gelenekçi düşüncelerinin yok olmasıyla daha fazla tüketilmeye başlanması olarak ifade edilmiştir.

Türk mutfağında füzyon uygulamalarına yaklaşım ölçeğinin "gelenekçi" alt boyutu ile sağlık problemi değişkenine göre, sağlık problemi olmayan bireylerin sağlık problemi olan bireylere göre daha gelenekçi olduğu tespit edilmiştir. Bu durum bireylerin sağlık durumlarını korumak ve günümüzde daha sağlıklı beslenme davranışı olarak yeni ürünleri birleştirme de ürüne aşina olmadıkları için önyargılı davranış göstermelerinden kaynaklı olduğu düşünülebilir. Spence (2017)'ye göre füzyon mutfağ yeni sunumların, tatların, renklerde olması nedeniyle füzyon mutfağında yer alan yemeklerin kutlamalarda daha çok yer almaya başladığı belirtilmiştir.

Türk mutfağında füzyon uygulamalarına yaklaşım ölçeğinin "gelenekçi" alt boyutu ile yurtdışı deneyim değişkeni olan bireylerin, yurtdışı deneyimi olmayan bireylere göre daha gelenekçi bir yaklaşım içinde oldukları tespit edilmiştir. Bu durumun yurt dışı deneyimi olan bireylerin yeni ürünleri zaman içinde daha kolay benimsemeye başlamalarından kaynaklandığı düşünülebilir. Doğdubay vd., (2017) çalışmalarında, yurtdışı deneyimi olan bireylerin yeni yiyecekleri tatmada çok seçici oldukları, farklı kültürlerden yiyecek sunan restoranlara gidenlerin çok az olduğu, sosyal etkinliklerde yeni yiyecekleri tatma konusunda gelenekçi bir davranış gösterdikleri belirtilmiştir.

Türk mutfağında füzyon uygulamalarına yaklaşım ölçeğinin "yenilikçi" alt boyutu ile yaş grupları değişkenine göre incelendiğinde, 23-27 yaş grubu arasında olan bireylerin, 33 ve üzeri yaş grubunda olan bireylere göre füzyon mutfağı uygulamalarında daha yenilikçi yaklaşım gösterdikleri belirlenmiştir. Bu durum küçük yaş grubunda olan bireylerin yeni tatlara ve lezzetlere daha meraklı ve ilgili olmalarından kaynaklandığı söylenebilir. Bekar ve Gövce (2015)'e göre 18-34 yaş aralığında olan bireylerin, daha önce tatmadıkları yeni yiyecekleri ve yabancı ülkelerin mutfaklarından lezzetler, tarifler denemeyi en çok seven grup olduğu tespit edilmiştir. Türk mutfağında füzyon uygulamalarına yaklaşım ölçeğinin "yenilikçi" alt boyutu ile bir yıl içinde yurt dışına çıkma sıklığı değişkeni incelendiğinde, bir yılda 1-3 arası yurt dışına çıkma sıklığı olanların puan ortalamaları düşük iken, 7-9 kez yurt dışına çıkma sıklığı olanların puan 
ortalamalarının yüksek olduğu saptanmıştır. Bu durum bireylerin yurt dişına çıkma sıklığ artıkça füzyon mutfağı uygulamalarına olan yeni ürün yaklaşımları arasında doğru ilişki olabileceğini doğrulamaktadır. Bireylerin yurtiçi ve yurtdışı seyahatler de bireylerin yeni yiyeceklere yaklaşımını etkilediği; yurtdışı deneyimi olan bireylerin yeni yiyecekleri tatmakta yeniliğe daha açık yaklaşım içinde oldukları tespit edilmiştir (McKercher vd., 2008; Sengel vd., 2015).

Türk mutfağında füzyon uygulamalarına yaklaşım ölçeğinin "şüpheci" alt boyutu ile yaş grupları değişkeni incelendiğinde, 18-22 yaş grubu puan ortalamaları düşük iken, 23-27 yaş grubu puan ortalamalarının yüksek olduğu belirlenmiştir. Bu durum sadece bu bulgu ile genellemeye gidilemez. Ama, Türk mutfağında füzyon uygulamalarına yaklaşım ölçeğinde yaş grupları yükseldikçe füzyon uygulamalarında yeni ürün tatma tecrübelerinde şüpheciliğin arttığ1 düşünülebilir. Hangi kültürde olursa olsun bireylerin aşina olmadıkları ürüne karşı şüpheci bir yaklaşım içinde oldukları söylenebilir. Poulain (2005)'e göre "haute cuisine" olarak belirtilen üstün nitelikli yemeklerin ilk kez tanıtıldığı Akdeniz tipi beslenme ve doğu reçetelerine de şüphe ile yaklaşıldığı ama zaman içinde bu duruma aşina olunduğu, aslında füzyon mutfak uygulamalarının tarihin ilk yıllarına dayanıldığı belirtilmiştir.

Türk mutfağında füzyon uygulamalarına yaklaşım ölçeğinin "şüpheci" alt boyutu ile bir yıl içinde yurt dişına çıkma değişkeni incelendiğinde, bir yılda 10 ve üzeri yurt dişına çıkma sıklığı olanların puan ortalamaları düşük iken, 1-3 kez yurt dışına çıkma sıklığı olanların puan ortalamalarının yüksek olduğu saptanmıştır. Bu durum bireylerin yurt dışına çıkma sıklığının az olmasına bağlı olarak yeni ürün deneme durumlarının da az olduğu ile parallelik gösterdiği söylenebilir. Menüde şişman ördek "The Fat Duck", yumurtalı dondurma gibi yeni füzyon ürünleri tanıtıldığında yeni ürünlerin karışımı merak edilse bile bir şüphe ile yaklaşıldığı aslında bu iki ürünün hem füzyon hem de bileşenlerin karıştırılmasını füzyon mutfağı uygulaması olduğu ifade edilmiştir (https://atasteofhistorywithjoycewhite.blogspot.com).

Türk mutfağında füzyon uygulamalarına yaklaşım ölçeğinin "gelenekçi" alt boyutu ile yaş grupları değişkeni incelendiğinde, hem 18-22 yaş grubunun hem de 33 ve üzeri yaş grubunun puan ortalamalarının düşük olduğu saptanmıştır. Bu durum çalışmada yer alan bireylerin füzyon mutfağı uygulamalarında küçük yaş grubuna bağlı olarak Türk Fransız ve Türk İtalyan mutfağ yemeklerinin isimlerini ilk kez duymuş olmalarından kaynaklı olarak geleneksel tatların dışına çıkmak istemeyen bir grup olduğu düşünülebilir. Ancak, bireylerin menüde ilk kez parmesanlı dondurma bir füzyon ürünü olarak gördüklerinde umami tatlara karşı hiç tadılmadığı için gelenekçi bir yaklaşım gösterdikleri, aslında bunların bir füzyon mutfak uygulaması olduğu, menüde içindekilere karşı iki bilinen ürünün hem füzyon hem de bileşenlerin karıştırılması olarak ifade edilmiştir (https://atasteofhistorywithjoycewhite.blogspot.com).

Türk mutfağında füzyon uygulamalarına yaklaşım ölçeğinin "şüpheci" ve "yenilikçi" alt boyutu arasında pozitif yönde, "gelenekçi" alt boyutunda ise negatif yönde ilişki bulunmuştur. Füzyon mutfak uygulamaları, geleneksel mutfak kültürüne alışkın toplumlar için yeni bir mutfak akımı olup, bu akımda sunulan ürünlerin tamamı yeni birer gastronomik ürün olarak ele alınabilir. Dolayısı ile "gelenekçi" alt boyutunda ilişkinin negatif çıkması, Türk toplumunun geleneksele olan yöneliminden kaynaklanmaktadır. Türk mutfağının gelenekselliğine fazlaca bağlı olan bireylerde yeni yiyeceklere yaklaşım, hele ki yurtdışı kaynaklı bileşenlerle meydana getirilmiş ürünlere bakış açısını değiştirmek çoğu zaman oldukça güçtür.

Çalışmadan elde edilen veriler ışığında aşağıdaki öneriler getirilmiştir:

- Bu çalışmada Türk mutfağında füzyon uygulamaları Fransız ve İtalyan mutfaklarının harmanlanmasıyla oluşturulmuştur. Farklı ülke mutfakları ile Türk mutfağında füzyon uygulamaları belirlenerek de bireylerin eğilimleri tespit edilebilir. 
- Çalışma, Kültür ve Turizm bakanlığından seçilen örneklem ile sınırlıdır. Toplumun farklı kesimlerinden bireylere uygulanacak çalışmalarla sonuçlar genişletilebilir veya farklı sonuçlar elde edilebilir.

- Çalışma bireylerin yeni yiyeceklere yaklaşımlarını füzyon mutfak bağlamında belirlemeye çalışmıştır. Yeni yiyeceklere yaklaşım farklı konularla da ele alınabilir.

- Bireylerde oluşan Türk mutfağında füzyon uygulamalarına yaklaşımda çekinme ve kaçınma durumlarına karşın; işletmeler, füzyon ürünlerinin güvenilir, lezzetli ve yenilebilir olduğuna yönelik tanıtıcı faaliyette bulunabilirler.

- Füzyon uygulamalarına şüpheci yaklaşan bireylerin, bu ürünlerin içeriklerini araştırmaları, bileşenlerini öğrenerek önyargılarının yok olmaları sağlanabilir.

- Çeşitli gastronomi festivallerinde füzyon mutfak uygulamalarına yönelik gösterimler ve tanıtımlar katılımcıların farkındalıkları arttırılabilir.

\section{KAYNAKÇA}

Akbaş, U., Aydoğdu, Ş. ve Büyüköztürk, Ş. (2020). Farklı Ortamlarda Uygulanan Likert Tipi Ölçek ile Metrik Ölçeğin Psikometrik Özelliklerinin İncelenmesi, Hacettepe Üniversitesi Eğitim Fakültesi Dergisi, 35(1): 222-242. https://doi:10.16986/HUJE.2019050088.

Albors-Garrigos, J., Haddaji, M. and Garcia-Segovia, P. (2020). Gender Discrimination in Haute Cuisine: A Systematic Literature and Media Analysis, International Journal of Hospitality Management, 89: 1-12. https://doi.org/10.1016/j.ijhm.2020.102569

Arman, A. (2011) Türk Mutfak Kültürü Tanıtım Sorunu: Mengen Mutfağı Örneği, Yüksek Lisans Tezi, Düzce Üniversitesi Sosyal Bilimler Enstitüsü, Turizm İşletmeciliği ve Otelcilik Anabilim Dalı, Düzce.

Arslan, S. (2015). İtalyan Mutfağının Özellikleri. http://nasilkolay.com/italyan-mutfagininozellikleri [Erişim Tarihi: 07.02.2021].

Bekar, A. ve Gövce, A.M. (2015). Tüketicilerin Gıda Satın Alma Davranışları ile Yaşam Tarzı İlişkisi, Uluslararası Sosyal Araştırmalar Dergisi, 8(36):946-557. https://www.sosyalarastirmalar.com/cilt8/sayi36_pdf/8digersosyalbilimler/bekar_aydan_meteh an.pdf

Benedict, A. (1991). Imagined Communities. Londra-New York: Verso.

Bhabha, H. (1994). The Location of Culture. Londra: Routledge.

Blake, I. (2017). You Batter Believe It! Fish and Chips Are NOT British (And We Have Immigrants to thank for the Nation's Favorite Takeaway). [Daily Mail Online], March 14 http://www.dailymail.co.uk/femail/food/article-4312420/UK-takeawayfavourite-fish-chips-notBritish.html [Erișim Tarihi: 07.03.2021].

Bourdain, A. (2018). Pasta Pane Vino Deep Travel through Italy's Food Culture. Italy: Roads \& Kingdoms, pp: 150-615.

Brittin, H.C. (2011). The Food and Culture around the World Handbook. Boston, Massachusetts: Prentice Hall.

Büyüköztürk, Ş., Çakmak, E.K., Akgün, Ö.E., Karadeniz, Ş. ve Demirel F. (2012). Bilimsel Araştırma Yöntemleri. Ankara: Pegem.

Can, A., Sünnetçioğlu, S. ve Durlu-Özkaya, F. (2012). Füzyon Mutfağı Uygulamalarının Gastronomi Turizminin Gelişimine Katkısı, 13. Ulusal Turizm Kongresi, 6-9 Aralık, Antalya. 
Castelman, E.G. (2003). Northern Italy. S. H. Katz and W. W. Weaver (Ed.), Encyclopedia of food and culture içinde (ss. 298-303). New York: Scribner.

Chiaro, D. and Rossato, L. (2015). Food and Translation, Translation and Food, The Translator, 21(3): 237-243. https://doi.org/10.1080/13556509.2015.1110934

Çakıcı, N. ve Eser, S. (2016). Yabancı Mutfak Şefleri Gözüyle Türk Mutfağına İlişkin Bir Değerlendirme, Journal of Tourism and Gastronomy Studies, 4(Special issue1): 215-227.

Della, S. (2017). Cucina Italiana. Italyan Mutfağı Haftası, 20-26 Kasım, İstanbul. http://iicistanbul.esteri.it/iic_istanbul/resource/doc/2017/11/brosur_cropsuz_baski_cift_edit.pdf

Del Moral, R.G. (2020). Gastronomic Paradigms in Contemporary Western Cuisine: From French Haute Cuisine to Mass Media Gastronomy, Frontiers in Nutrition, 6,1-12. https://dx.doi.org/10.3389\%2Ffnut.2019.00192.

Demirkol, N. (2013). Bir Masa Etrafında Toplanmak: Kültürlerarasılığın Hayata Geçirilme Alanı Olarak Sofra ve Mutfak. Aynı Tadı Paylaşmak: Türkiye-Romanya Geleneksel Ortak Mutfağı Çalıştay Bildirileri, Ankara: Unesco $\quad$ Yayınları: 23-30. https://www.unesco.org.tr/Content_Files/Content/Yayinlar/romanya_g_o_m.pdf\#page=36 [Erişim:08.03.2021].

Denizer, D. (2008). Türk Turizminin Gelişmesinde Türk Mutfağının Önemi ve Bugün için Yapılması Gerekenler, II. Gastronomi Sempozyumu ve Sanatsal Etkinlikler, 10-11 Nisan, Antalya.

Doğdubay, M., Şahin, N.N. and Yiğit, S. (2017). In the Fusion Cuisine Approach Availability of Quinoa (Application Suggestions), Journal of Tourism and Gastronomy Studies, 5(3): 3-12.

Erkuş, A. (2013). Davranış Bilimleri İçin Bilimsel Araştırma Süreci. Ankara: Seçkin.

Field, A.F. and Smith, M.E. (2001). False memories: The invention of culinary fakelore and food fallacies. Oxford Symposium on Food and Cookery; Food and the Memory, 254-260. Prospect Books, Oxford, UK.

Geiling, N. (2013). Sorry, Wolfgang, Fusion Foods Have Been with Us for Centuries. The Smithsonian, July 24th. 〈https://www.smithsonianmag.com/arts-culture/sorrywolfgang-fusion-foods-havebeen-with-us-for-centuries-17238814/>.

Girgin, G.K., Demir, Ö. ve Çetinkaya, V. (2017). Dünyanın En İyi Mutfakları ve Türk Mutfağı, Journal of Tourism and Gastronomy Studies, 5(2): 219-229.

Guzek, D., Pęska, J. and Głąbska, D. (2019). Role of Food Neophobia and Allergen Content in Food Choices for a Polish Cohort of Young Women, Nutrients, 11(11):1-15. https://doi.org/10.3390/nu11112622

Güler, S. (2010). Türk Mutfak Kültürü ve Yeme İçme Alışkanlıkları, Dumlupınar Üniversitesi Sosyal Bilimler Dergisi, 26: 24-30.

Hannerz, U. (1998). Çevre Kültür Senaryolart-Kültür Küreselleşme ve Dünya-Sistemi: Kimlik Temsilinin Çağdaş Koşulları. Der: Anthony D. King, (Çev: Seçkin, G. ve Yolsal, Ü. H.) Ankara: Bilim ve Sanat Yayınları: 139-163.

https://atasteofhistorywithjoycewhite.blogspot.com/2016/08/parmesan-ice-cream-i-am-notkidding-you.html [Erişim Tarihi: 08.03.2021].

Karamustafa, K., Birdir, K. ve Kılıçhan, R. (2016). Gastronomik Akımlar Çerçevesinde Gıda Tüketim Ölçeği, Tüketici ve Tüketim Araştırmaları Dergisi, 8 (2): 29-69. 
Katona-Apte, J. (2003). Southern Italy. S. H. Katz and W. W. Weaver (Ed.), Encyclopedia of food and culture içinde (ss. 303-307). New York: Scribner.

Kawasaki, H. and Shimomura, K. (2015). Temporal Design of Taste and Flavor: Practical Collaboration between Chef and Scientist, Flavour, 4(12): 1-4. https://doi.org/10.1186/2044-7248-412

Kılıçer, K. ve Odabaşı, H. F. (2010). Bireysel Yenilikçilik Ölçeği (BYÖ): Türkçeye Uyarlama, Geçerlik ve Güvenirlik Çalışması, Hacettepe Üniversitesi Ĕ̆gitim Fakültesi Dergisi (H. U. Journal of Education), 38: 150-164.

Kırım, A. (2005). Füzyon Mutfağı Nedir Bize Ne Kadar Uyar? http://www.hurriyet.com.tr/fuzyonmutfagi-nedir-bize-ne-kadar-uyar-38739240 (Erişim Tarihi: 25.01.2021).

Kittler, P.G., Sucher, K.P. and Nelms, M.N. (2012). Food and Culture. (6th Edition). Wadsworth: Cengage Learning.

Köksal Sezgin, E. (2020). Fransız Mutfağı, https://www.academia.edu/4042779/FRANSIZ_MUTFAGI?auto=download, [Erişim Tarihi: 26.01.2021].

Küçük, B. ve Kahyaoğlu, İ. (2013). Yerellik Öğeleri İçinde Küreselleşen Yönetmen: Ferzan Özpetek, The Turkish Online Journal of Design, Art and Communication-TOJDAC, 3(2): 57-66.

Lane, C. (2019). Reverse Cultural Globalization: The Case of Haute Cuisine in One Global City, Poetics, 75: 1-13. https://doi.org/10.1016/j.poetic.2019.02.001

Lawrence, R.G. (2019). Pot in Pans: A History of Eating Cannabis. Edt. Kilham Chris. London: Rowman and Littlefield.

MacVeigh, J. (2009). International Cusine. Clifton Park, New York: Delmar Cengage Learning.

McKercher, B., Okumuş, F. and Okumuş, B. (2008). Food Tourism as a Viable Market Segment: It's All How You Cook the Numbers! Journal of Travel and Tourism Marketing, 25(2): 137-148.

Mil, B. (2009). Yemek Pişirmede Gastronomiye Uzanan Bakış Açısıyla Küreselleşen Yemek, III. Ulusal Gastronomi Sempozyumu ve Sanatsal Etkinlikler, 17-18 Nisan, Antalya.

Oktay, S. and Sadıkoğlu, S. (2018). The Gastronomic Cultures' Impact on the African Cuisine, Journal of Ethnic Foods, 5(2): 140-146. https://doi.org/10.1016/j.jef.2018.02.005

Olabi, A., Neuhaus, T., Bustos, R., Cook-Camacho, M., Corvi, T. and Abdouni, L. (2015). An Investigation of Flavor Complexity and Food Neophobia, Food Quality and Preference, 42: 123-129.

Özdamar, K. (1999). Paket Programlar ile İstatistiksel Veri Analizi-1. Eskişehir: Kaan Kitabevi.

Özen, A.E. (2016). Güney Avrupa Mutfağı. H. Kurgun ve D. B. Özşeker (Ed.), Gastronomi ve Turizm içinde (ss. 205-231). Ankara: Detay.

Parasecoli, F. (2011). Europe: Italy. Food Cultures of the World Encyclopedia içinde (ss.207-217). California: Greenwood.

Petruzzelli, A. M. and Savino, T. (2015). Reinterpreting Tradition to Innovate: The Case of Italian $\begin{array}{llll}\text { Haute } \quad \text { Industry and } & \text { 677-702. }\end{array}$ https://doi.org/10.1080/13662716.2015.1122512

Poulain, J. P. (2005). French Gastronomy, French Gastronomies. Golstein, D., Merkle, K. and Mennell, S. (Ed.) Culinary cultures of Europe: Identity, diversity and dialogue içinde (ss.157-169). Strasbourg: Council of Europe Pub. 
Presenza, A., Abbate, T., Casali, G. L. and Perano, M. (2017). An Innovative Approach to the Intellectual Property in Haute Cuisine, International Journal of Hospitality Management, 65: 81-88. https://doi.org/10.1016/j.ijhm.2017.06.009

Privitera, D., Nedelcu, A. and Nicula, V. (2018). Gastronomic and Food Tourism as an Economic Local Resource: Case Studies from Romania and Italy, Geojournal of Tourism and Geosites, 1(21): 143-157. http://gtg.webhost.uoradea.ro/

Reed, D. R., Tanaka, T. and McDaniel, A. H. (2006). Diverse Tastes: Genetics of Sweet and Bitter Perception. Physiology \& Behavior, 88: 215-26. https://doi.org/10.1016/j.physbeh.2006.05.033

Renna, M., Rinaldi, V.A. and Gonnella, M. (2014). The Mediterranean Diet between Traditional Foods and Human Health: The Culinary Example of Puglia (Southern Italy), International Journal of Gastronomy and Food Science, 2:63-71.

Sandıkçı, M. ve Çelik, S. (2007). Füzyon Mutfak Uygulamaları ve Müşteri Memnuniyeti Açısından Önemi, 1. Ulusal Gastronomi Sempozyumu ve Sanatsal Etkinlikler, 4-5 Mayıs, Antalya.

Sarışık, M. (2016). İtalyan Mutfağı (Ünite 2). H. Yılmaz (Ed.), Dünya Mutfakları-1. Eskişehir: Anadolu Üniversitesi Yayınları, s: 28-53.

Sengel, T., Karagöz, A., Çetin, G., İstanbullu-Dinçer, F., Ertuğral, S. M. ve Balık, M. (2015). Tourists' Approach to Local Food, Procedia-Social and Behavioral Sciences, 195: 429-437.

Spence, C. (2017). Comfort Food: A Review, International Journal of Gastronomy and Food Science, 9: 105-109.

Spence, C. (2018). Contemporary Fusion Foods: How Are They to Be Defined, and When Do They Succeed/Fail?, International Journal of Gastronomy and Food Science, 13:101-107.

Tarınç, A., Yıldırım, G. ve Kılınç, C. Ç. (2019). Osmanlı Mutfağının Füzyon Mutfağı Çerçevesinde Değerlendirilmesi, Journal of Social and Humanities Sciences Research, 6(43): 3045-3053.

Tarr, A. (2016). Food and Culture from Local Relationality to Global Responsibility, Journal of Dialogue and Culture, 5(1): 52-62.

Tupini, P. A. (2016). A Gastronomy Unaffected by the Economic Crisis: Ethnic Cuisine Knows No Geographical or Cultural Frontiers, Conservation Science in Cultural Heritage, 16: 315-18. https://doi.org/10.6092/issn.1973-9494/7174

Turan, H., Başaran, G., Ayduğ, İ., Bayesen, D. ve Sünnetçioğlu, S. (2020). Mutfak Şeflerinin Füzyon Mutfağa Yönelik Görüşleri ve Çanakkale İline Ait Yöresel Gidalar ile Füzyon Mutfak Önerileri, AHBVÜ Turizm Fakültesi Dergisi, 23 (2): 332-358.

Vargas-Sanchez, A. and Lopez-Guzman, T. (2015). Contemporary Management and Innovation: Learning from the Gastronomy Sector, Journal of Food, Agriculture \& Environment, 13 (1): 32-38.

Weichselbaum, E., Benelam, B. and Costa, H.S. (2009). Traditional Foods in Europe. $6^{\text {th }}$ Eurofir Synthesis Report, British Nutrition Foundation. London: Institute of Food Research.

Wright, L., Nancarrow, C. and Kwok, P. (2001). Food Taste Preferences and Cultural Influences on Consumption, British Food Journal, 103: 348-357. https://doi.org/10.1108/00070700110396321

Yıldız, E. (2016). Fransız Mutfağı (Ünite 1). H. Yılmaz (Ed.), Dünya Mutfakları-1. Eskişehir: Anadolu Üniversitesi Yayınları, s:2-27.

Yiğit, S. (2018). Etnik Mutfak Ürünlerinin Tercihinde Neofobinin Etkisi: Karşılaştırmalı Bir Uygulama, Yüksek Lisans Tezi, Balıkesir Üniversitesi Sosyal Bilimler Enstitüsü, Gastronomi ve Mutfak Sanatları Anabilim Dalı, Balıkesir. 
Yorgancı, B. (2018). Gastronomi Turizmi ve Kapadokya'nın Gastronomik Unsurları Hakkındaki Turist Algılarının Araştırılması, Yüksek Lisans Tezi, Nevşehir Hacı Bektaş Veli Üniversitesi Sosyal Bilimler Enstitüsü, Turizm İşletmeciliği Anabilim Dalı, Nevşehir.

Zainal Abidin, M. R.; Che Ishak, F.A., Ismail, I. A. and Juhari, N.H. (2020). Modern Malaysian Cuisine: Identity, Culture, or Modern-Day Fad?, International Journal of Gastronomy and Food Science, 21: 1-9. https://doi.org/10.1016/j.ijgfs.2020.100220 